\title{
ACERCA DE UMA INTERPRETAÇÃO JURÍDICO-FILOSÓFICA DO FAUST
}

\author{
RENATO CIRELL CZERNA, \\ Auxiliar de ensino da Cadeira de Introdução \\ à Ciência do Dlreito, da Fac. de Direito.
}

WILHELM SAUER, em seu "Juristische Methodenlehre" (Stuttgart, 1940,624 pp.), o mais recente e, sem dúvida, o mais importante de seus livros, o qual mereceria ser objeto de uma análise crítica detalhada, apresenta um breve estudo intitulado "Contribuição para uma explicação do Fausto de Goethe" (Zur Deutung von Goethes Faustdichtung). Tratase de uma interpretação, à luz das teorias e doutrinas do autor, daquilo que, para ele, constitui o problema jurídico-filosófico fundamental da tragédia goethiana, e cuja solução lhe parece poder invocar em apoio de sua própria posição. Abordaremos adiante o conteúdo da interpretação de Sauer, entrando no mérito da questão. Desde já, porém, podemos observar que a própria análise do Faust à luz da Idéia do Direito e da Justiça, evoca problemas dignos de serem ventilados, ainda que muito brevemente. Para nós, êles constituirão ocasião de algumas reflexões à margem de sua solução.

A maneira pela qual o Direito é considerado, logo de início, no Fausto, não é muito lisongeira. Efetivamente, quando Faust, depois de concluído o pacto com o demônio, prepara-se para iniciar a grande e aventurosa viagem, um jovem, que vem de longe à sua procura, para iniciarse no caminho do saber, é recebido por Mefisto o qual, fingindo ser Faust, com êle se entretém acêrca dêsse e daquele ramo do conhecimento; e em dado momento exprime, com as seguintes palavras, a sua opinião (que aqui é também a do poeta) sôbre o direito:

Ich weiss wie es um diese Lehre steht, Er erben sich Gesetz und Rechte Wie eine ew'ge Krankeit fort!

Sie schleppen von Geschlecht sich zum Gesch[lechte 
Und ruecken sacht von Ort zu Ort. Vernunft wird Unsinn, Wohltat Plage, Weh dir, dass du ein Enkel bist! Vom Rechte, das mit uns geboren ist, Von dem ist, leider, nie die Frage.

Eu sei o que se dá com esta ciência, As leis e os direitos se reproduzem Como uma eterna moléstia.

Arrastam-se de geração em geração E suavemente vão de um lugar para outro. Razão torna-se contrasenso, o benefício praga, Daquele direito que nasceu conosco Infelizmente nunca se ouve falar.

Eis aí, encerrada nesse poucos versos, tôda uma problemática. Já à primeira vista, é evidente que a palvra "direito" é tomada em duas acepções. De um lado está o direito que, "como uma eterna moléstia se reprcduz de geração em geração", identificado, ou pelo menos equiparado à lei, tomada em seu sentido estrito; do outro, o direito "que nasceu conosco", do qual nunca se ouve falar, bem entendido, no mundo do direito positivo. O primeiro é o "direito legal" - perdoe-se o pleonasmo por assim dizer, o direito como conjunto de leis e de regras escritas, formalmente elaboradas, e ainda mais formal e rìgidamente aplicadas, enfim o "direito dos juristas", homens que tudo atrapalham, que nada resolvem, e os quais, por não serem capazes de, mediante um simples passe de mágica, resolver de maneira satisfatória tudo o que lhes é confiado, são considerados como inimigos. Daí, talvez, o ditado popular "Juristen boese Cristen", de que nos fala del Vecchio em seu estudo sobre " $\Lambda$ crise da Ciência do Direito" (1).

O outro, o "direito que nasceu conosco" é, ao contrário, encarado em certo sentido como direito justo, e talvez tenha profundas relações com o "direito natural", considerado como o direito racional, o direito inato à razão humana. O direito positivo, ao contrário, é aí considerado como uma obra de juristas, e parece bem identificar-se, pelo menos por ser tratado com o mesmo sarcasmo, com aquela "Juristerey", com aquela "Juris-sabença" (2), à qual Faust se refere em seu primeiro monólogo. 
A lei "que se reproduz como uma eterna moléstia" longe de ser considerada como expressão da ordem objetiva que protege e coordena, senão condiciona, "o direito subjetivo" "inato" (como queria o poeta), parece o seu maior inimigo, é o arbítrio, é a méra forma abstrata, requer obediência à letra, e não procura conciliar-se com as circunstâncias humanas, oposta que é à espontaneidade do direito "vivo", inimiga que é do direito "hưmano", que força rìgidamente dentro de seu esquema. Aliás ,quanto à imperfeição do "direito positivo", poder-se-ia, desde já, considerar, com Mircea Djuvara (3) que êle é um produto real do pensamento humano, e não o pensamento mesmo. Porisso possui todos os inconvenientes das criações do pensamento humano "é aperfeiçoavel, e porisso mesmo provisório, incompleto e imperfeito; constitui um objeto determinado do conhecimento, e suas prescrições por sua natureza lógica, têm um caráter de fixidez e não se adaptam perfeitamente à vida. Mas, com esta preliminar justificação do direito positivo e de sua imperfeição, entrariamos em polêmica com Goethe, quanto ao mérito da questão, o que não é absolutamente nosso intento.

Quanto à aludida posição inical do Poeta, trata-se, enfim, da oposição entre formalismo e vida, entre as exigências de uma justiça que deve tender a concretizar-se, e o formalismo de uma ordem jurídica que tende a garantir a segurança social. De outro prisma, entretanto, esta posição se relaciona estritamente com a oposição entre "Direito Natural", como direito ideal, e direito positivo; mesmo porque, a consideração da Justiça enquanto deve concretizar-se e que, nisto, se identifica com o aspecto dinâmico do direito, como o polo oposto à sua função formal e estática, transforma-se, por um princípio dialético, na consideração da Justiça enquanto ponto de referência, ou seja da Justiça à qual o fato, em que ela se concretiza, deve referir-se, e que portanto deve transcender o fato, para que êste possa a ela referir-se e para que, por conseguinte, ela mesma possa no fato concretizar-se; dêste segundo ponto-de-vista, a Justiça é antes estática do que dinâmica, antes formal do que concreta; mais ainda, poderíamos dizer, num aparente paradi xo, que ela é abtrata e transcendente, para que possa tornar-se concreta.

Deixemos, porém, êste ponto, e consideremos a oposição entre formalismo e vida, como aparece nos citados versos goetheanos. 
A Idéia do Direito não se refere a um sistema de direito positivo, nem é só o conceito lógico de direito, como síntese daqueles caracteres a priori que fazem com que o direito seja direito em todos os tempos e latitudes; ou melhor, não é só em função de seu conceito lógico strico sensu que o direito é tal. Por outrc lado, o ponto-de-vista lógico e o pontode-vista ético - o que diz mais respeito ao conteúdo concreto de cada ordem jurídica - não constituem dois campos inimigos e inseparáveis, mas estão unidos, um em função do outro, num todo que os transcende e condiciona. A Idéia de Direitc, por ser êste todo, não sé identifica com o conceito lógico universal, digamos assim, do Direito, nem só com o seu aspecto ético. Ambos são momentos daquela, a qual é a síntese de ambos, representa o dever-ser jurídico e de certa maneira coincide, latosensu, com a Idéia de Justiça. Justiça que se realiza funcionalmente num processo contínuo, porque representa uma concretização nunca realizada e acabada, uma concretização condicionada pela dialética entre a imperfeita realização temporal da Justiça, por vêzes negativa em seu $s e_{r}$, mas sempre afirmativa em seu dever-ser, e o ideal de Justiça ao qual necessàriamente se refere para poder realizar-se e enquanto se realiza, ideal que a transcende mas que nela se concretiza.

Este problema toca muito de perto outro, o do direito natural, sem dúvida o fulcro das divergências dos juristas e das escolas de todos os tempos. Para melhor esclarecimento digamos apenas (pois que não poderíamos abordar o problema em si mesmo) que o direito natural, na ordem das idéias acima, não deve ser considerado como correspondente à "ordem natural das coisas", nem como princípio strictu-sensu racional, nem mesmo como valor ideal imóvel, meta final de todos os direitos positivos, mas sim como correspondente à funcionalidade da Idéia do Direito - que é dever-ser e se revela numa concretização relativa - como condicionante lógico-ético da possibilidade do direito. Ele bifurca-se, digamos assim, num sentido lógico, como o condicionante funcional da juridicidade de todo e qualquer sistema de direito, (nunca quanto ao conteúdo - "justiça", mas quanto à forma lógica) e em sentido ético como o condicionante funcional da tendência formal à Justiça, de qualquer direito; aquêle é a forma dêste conteúdo (justiça), que por sua vez é forma dos conteúdos históricos que a ela se referem. $O$ direito natural é tal, sòmente no sentido de condição válida e transcendente com respeito a todo sistema histórico e positivo. 
Por outras palavras, se nós tivéssemos de entender o direito natural como uma espécie de substrato constante das modificações do direito no tempo e no espaço, diríamos que o real substrato, neste sentido, é, por um lado, a forma lógica "jurídica" de todos os fatos que correspondem à categoria "direito", ou seja, aquilo que faz com que possamos falar de direito, apesar da variabilidade dos sistemas jurídicos; o que há aqui, não é a adequação e nem sequer a referência de um qualquer sistema jurídico a um conceito lógico fixo e imóvel de direito, o que há é, neste caso, a forma como condição funcional dessa possibilidade: o substrato, aqui, é o conjunto dos princípios lógicos que condicionam funcionalmente essa possibilidade; êste é o que podem denominar o ponto-devista da FORMA, o aspecto puramente lógico desse substrato que alguns denominaram, equivocadamente, "direito natural"; por outro lado, há o aspecto do conteúdo, ou seja: o que faz com que o direito seja direito, quaisquer sejam o tempo e o espaço em que êle se realiza històricamente, é a sua referencia à Idéia de Justiça. Esta referência, entretanto, justamente de imperfeito com referência à realização da Justiça, cuja condência de seu conteúdo com "a Justiça" mas a referência, a ela, referência que é comum a todos os possíveis sistemas de direito, os quais são entretanto diversos, e, possìvelmente opostos, em seu conteúdo concreto. Esta referência formal ao valor da Justiça, portanto, é conteúdo em relação à forma lato-sensu lógica de que acima falamos, mas é por sua vez, forma em relação ao conteúdo concreto e histórico de sua realização. Êste é o aspecto ético do problema. Num e noutro, porém, dos dois aspectos em que o problema se divide, o que existe é um conjunto de princípios funcionais que condicionam dialèticamente o substrato de que se falou.

Voltando ao Faust, depois desta divagação necessária, podemos dizer que quanto ao que nos interessa, êle constitui uma posição negativa para com o direito positivo, o "direito dos juristas", no que êle tem justamente de imperfeito com referência à realização da Justiça, cuja concretização é por vêzes impedida pelo excessivo e preponderante formalismo; mas constitui uma posição afirmativa, por isso mesmo, com referência à mesma justiça, e portanto também à Idéia de Direito. Estas duas posições canstituem a expressão da cposição entre o direito histórico e Idéia de Direito, que por sua vez constituem o dualismo em que se divide o processo em si unitário do direito. O direito não é nenhum dos dois têrmos, mas é a unidade dialética de ambos; e esta é a única maneira de superar a necessária oposição. Esta oposição é que pre- 
cede e condiciona a síntese que representa a essência do direito e da justiça, o seu processo dialético. E tôda a tragédia de Goethe é expressão dêste princípio dialético.

Com isto voltamos, pois, à oposição entre formalismo e justiça, oposição que quase dois séculos antes, outro grande espírito, maravilhoso analisador de sentimentos humanos, Shakespeare, tratara, no famoso episódio, de todos conhecido, de Shylock. Este, com efeito, em virtude de um contrato que havia sido infringido, tinha direito a uma libra de carne viva do infeliz devedor. O Juiz, ao qual recorre, para salvar a vítima da ferocidade "jurídica" do mercador, determina que êste receba uma libra de carne de seu devedor, mas com a condição de não tirar-lhe uma só gota de sangue, pois êste não era contemplado pelo contrato. Houve, como lembra del Vecchio (4), uma polêmica famosa entre von Thering e Joseph Kohler, a respeito da decisão do juiz, o qual, mediante o seu sofisma, teria agido, conforme o primeiro dos dois grandes juristas, de forma contrária ao direito, prescindindo, naturalmente, do fato de que o aludido pacto deveria ser considerado nulo, e o seria por qualquer jurista moderno, em virtude de ser contrário à ordem pública e aos bons costumes, e sempre, portanto, admitindo-se a sua validade de acôrdo com a ordem jurídica vigente na ocasião.

Deixando de lado os problemas estritos de interpretação, inerentes ao fato em aprêço, e mesmo as conclusões de del Vecchio, que quer ver em Shylock o tipo mais extremado possível, em certo sentido, do "Homo juridicus", consideremos que, quanto ao que nos interessa, estamos aqui, ainda uma vez, em face do conflito entre rígido formalismo e a exigência de uma justiça concreta e da realização de um direito consentâneo com esta exigência humana.

Só humana? Não para Goethe. Porque, com efeito, - e aqui chegamos ao ponto essencial destas considerações - o problema de Shakespeare ressurge, de certo modo, no Faust, mas de maneira ainda mais universal; poderíamos dizer mesmo que, do ponto-de-vista filosófico-jurídico, a essência do Faust consiste num contrato não cumprido em que o infrator não sofre a pena cominada por aquêle. A história de Faust é a história de um homem que faz um contrato com o demônio, o qual, no fim, é ludibriado porque, apesar de ganha a aposta, não recebe o que era seu, a alma de Faust que êste lhe vendera, digamos assim, sob condição suspensiva, que se verifica sem que, contudo, tenha os efeitos devidos. Aqui, Deus é o juiz, Mefisto Shylock e Faust o devedor. 
Nesta ordem de idéias chegamas a duas considerações interessantes; ou seja, que, de certo modo, todo o Faust cifra-se, lato-sensu, se quisermos captá-lo em seu caráter mais geral, em têrmos filosófico-jurídicos, e mais ainda o seu problema fundamental é um problema lato sensu jurídico, por ser um problema de Justiça, de interpretação do sentido da Justiça; por outro lado êsse mesmo problema revela uma profunda dialética entre formalismo e justiça concreta e é ao mesmo tempo expressão dialética que anima tôda a tragédia. No Faust, a idéia dialética ultrapassa a esfera do puramente jurídico, mas será sempre essa idéia do Direito que, justamente enquanto ultrapassada como puramente tal, indicará aquela totalidade.

A trama da Tragédia consiste, como é sabido, em que Faust, doutor e alquimista medieval, profundamente inquieto e insatisfeito, conclui com o demônio um pacto pelo qual êste se obriga a proporcionarthe a plenitude de uma vida repleta de novos conhecimentos, de prazeres e de poder. E Faust, em troca, obriga-so a dar a Mefisto a sua alma, se algum dia reconhecer esta plenitude e declarar-se satisfeito com ela, o que entretanto, afirma implìcitamente, nunca se dará. São os célebres versos:

Werd'ich dem Aungenblicke sagen:

Verweile doch! Du bist so 'schoen!

Dann magst du mich in Fesseln schlagen,

Dann will ich gern zugrunde gehn.

Se eu disser ao momento:

Permanece, és tão belo!

Poderás deitar-me grilhões,

De bom grado perecerei.

E, efetivamente, no fim da vida, chega o momento de suprema ventura, do qual Faust afirma:

Dem Augenblicke duerft,ich sagen:

Verweile doch! Du bist so schoen!.

Ao momento eu poderia dizer:

Permanece, és tão belo!

Faust, portanto, perde a aposta. E Mefisto, com satisfação, constatało: Parou o relógio, parou o ponteiro. 
Die Uhr steht still.

Steht still,

.Der Zeiger faellt.

Assim mesmo, porém, o pacto que devia ser cumprido, em virtude daquela aposta, não é cumprido. Os anjos, intervindo no último momento, levam a alma de Faust ao Paraíso. E Mefisto exclama, irritado: "Quem me garante o meu direito adquirido?"

\section{Wer schafft mir mein erworbnes Recht?}

$\mathrm{Na}$ interpretação de Sauer, entretanto, Mefisto só tem razão em relação à sua aposta com Faust; mas acontece que êle havia efetuado também outra aposta, e esta com Deus, aposta que Deus mesmo, depois de permitir a Mefisto tentar "afastar êsse espírito (Faust) de sua fonte originária (a Unidade da qual provinha)" ("Zieh diesen Geist von seinem. Urquell ab!") assim sintetiza:

Und steh beschaemt wenn du erkennen musst:

Ein guter Mensch in seinem dunklen Drange

Ist sich des rechten Weges wohl bewusst!

"Envergonhado terás de reconhecer que um homem bom, em seu obscuro impulso, bem conhece o caminho certo"

$\mathbf{E}$ quando os anjos levam a alma de Faust ao Empíreo declaram confirmando:

Wer immer strebend sich bemueht

Den koennen wir erloesen.

Podemos salvar a quem sempre se preocupa em tender, superando".

Com efeito, diz Sauer, em que pese o seu pacto com Mefisto, Faust sempre tenda à realização de valores. $\mathbf{E}$ como êsses valores são eternos, Faust não pode perder-se. "Os traços de meus dias terrenos, não" podem descer aos infernos":

Es kann dis Spur von meinen Erdetagen

Nicht in Aeonen untergehn. 
Mefisto, emquanto potência inferior, não compreende os valores aos quais tende Faust. Só o espírito humano, só o homem, que "é cidadão de dois mundos" deus e demônio, age em referência a valores, ou seja, princípios válidos que transcendem a vida e a realidade material. $\mathrm{Me}$ fisto pensa de maneira formalista "bidimensional", enquanto que Faust raciocina e sente "tridimensionalmente".

No dizer de Sauer, no "Faust" está melhor do que nunca expresso o famoso princípio da "tridimensionalidade", cuja paternidade o citado pensador alemão se atribui, se bem que saibamos que outros juristas filósofos, inclusive no Brasil, dêle trataram paralelamente ao citado jurista. De certo modo, enfim, tôda a grande polêmica entre direito natural, direito positivo, justiça e forma lógica do direito, valor e fato, resolve-se numa integração harmônica de fato, norma e valor, em que êste entra como uma espécie de "tertius", no conflito clássico entre norma e fato, entre a generalidade da norma e a individualidade de cada situação jurídica concreta. E assim também sana-se o conflito entre a interpretação puramente sociologista, que só quer ver o fato, e a puramente racionalista, que só considera o princípio gnoseológico, e tudo reduz a uma teoria do conhecimento jurídico. O direito, na sua acepção total, é, assim, sempre um fato, subsumido numa norma, que tende a um valor. No caso de Faust, o valor ao qual êle tende, salva a situação, que se fôsse resolvida só em função bidimensional, daria razão e ganho de causa a Mefisto.

Trata-se, sem dúvida, de uma doutrina extremamente engenhosa. Mas, para nós, ela encerra sobretudo o defeito de uma falta de unidade e de justificação da passagem de uma a outra das suas três esferas. Ao mesmo tempo cinde, indevidamente, o "fato" do princípio lógico, tornando aquêle puramente irracional e portanto, irredutível.

Tôda a doutrina revela rasgos geniais e uma poderosa tentativa de síntese. Mas de certa maneira fica apenas na tentativa e não consegue ultrapassá-la. Nem sequer a Idéia de método, que poderia ser imaginada como o elo de união das várias camadas, é realmente coerente. O método é interpretado por Sauer, não como a doutrina dos princípios, mas inclusive como tendo o fim de presidir à prática, e produzir os resultados que seus pressupostos prevêem. O que constitui, a nosso ver, logo de início, um salto de uma esfera a outra. 
A "Dreiseitenlehre", nos diz Sauer, sempre quanto ao problema do método, que aqui entretanto adquire um caráter menos acessório, “ .é o que distingue as ciências do espírito das ciências naturais". Muito bem. Sauer parte, também quanto às ciências do espírito, de um fato irredutivel, que repentinamente é estruturado por uma norma, fato irredutível êsse que aparece como Deus ex machina. A norma mesma, - o 2.0 princípio - através do qual o fato, por êle estruturado, move-se em direção ao valor, é pouco clara em sua significação. Com efeito, Sauer, por vêzes identifica-a - especialmente em sua descrição do fenômeno jurídico stricto sensu, com a lei, a norma jurídica, outras vezes - particularmente quando se trata das ciências do espírito em geral - com a categoria, o princípio gnoseológico, a lógica como estruturadora do fato em geral, e como princípio que lhe dá forma (Gestaltung) em direção e referência ao valor.

Ele não vê que tanto nas ciências do espírito como nas naturais, o objeto, o fato, já constitui uma projeção do espírito enquanto, ou fenô. meno que pela síntese com as leis estruturantes do espírito torna-se objeto, ou objeto surgido autônomamente no espírito (4) a diferença entre ambos está apenas em seu processo mas não em sua validez lógica. Já nas ciências naturais, portanto, seria ambíguo falar-se em "fato". De certo modo, a maneira pela qual Sauer fala às vêzes na "segunda dimensão" ( norma lógica, a estruturação do fato na teoria tridimensional, é um pleonasmo, porque o fato só é fato enquanto estruturado pelas leis do espírito.

Mas a ambiguidade dos três têrmos e de suas relações, e mesmo as contradições em sua consideração, são freqüentes. Para Sauer a "tridimensionalidade" é " .eine Methodenlehre die fuer Ausgang-Weg und Ziel .grundlegt" (uma doutrina do método, que fundamenta o ponto de partida, o caminho e o fim), em que "Ausgang" são os fatos e "Weg" a forma, (leis, normas) que englobam genèricamente os fatos - $e$ ainda assim para não cristalizar a Vida, e procurar manter o seu sentido - dirigindo-os para o Ziel - ou sejam os valores. Esta concepção fundamental é forçada, por ser pouco rigorosa quanto ao ponto-devista lógico, e no detalhe, como quando se refere aos valores, aos quais a vida, o ser, deve dirigir-se, através da norma, e contudo êsses valores. provêm da vida, são "Lebenswerte", e lhe são, de certa maneira, imanen- 
tes. Aparte a contradição, entretanto, aqui há o vício lógico de se falar em "Lebenswerte" quando na realidade a vida - admitia-se - recebe o seu "sentido" dos valores aos quais tende, e que a condicionam como tal.

Outras vêzes, contudo, o Autor troca simplesmente a validez de cada um dos têrmos, como quando afirma que nós vamos "Vom Leben zur Ewigkeit durch Kultur" (da vida (fato) para a eternidade (fim) através da cultura (meio), onde os valores são o meio, e não mais a norma. Mesmo porque o. Autor adverte prèviamente que a cultura é formada pelos valores. Em outra ocasião, o centro de gravidade parece ao contrário estar no $20^{\circ}$ princípio - aqui novamente a norma, o lógico, o formal - e portanto o primado do a priori lógico parece adquirir um novo vigor, como quando diz, por exemplo: "Der. Aufgabe (das Streben nach der totalen Wahrheit als harmonische Vereinigung der drei Groessen - Tatsachen Form und regulativen Werte) dient der formelle Wahrheitsbegriff, der mithin die doppelte Aurichtung zu pflegen hat: auf die Tatsachen und auf die absoluten Werte" (o conceito formal de verdade tem. a tarefa (a tendência à Verdade total, como reunião harmônica das três grandezas - fatos, norma e valores regulativos - e com isto deve observar a dupla direção: para os fatos e para os valores absolutos) (Juristische Methodenlehre, págs. 212-220). O que são, aqui, entretanto, "fatos" e "valores" e "valores regulativos"?

Quando Sauer descreve "o $20^{\circ}$ princípio" como "estruturação do fato", ou melhor, "o encaixamento do fato dentro de uma disposição, lei, etc., como determinada categoria lógica (o que, por exemplo, faz o juiz apreciando o fato bruto e tornando-o fato jurídico)" o seu raciocínio já começa num degrau muito "adiantado", que pressupõe tôda uma análise do próprio princípio lógico, análise essa, não realizada. Chega-se assim a uma paralelismo arbitrário, mas implìcitamente admitido, entre a função e o processo de estruturar o fato bruto como fato jurídico, revestindo-o de uma forma jurídica, enquanto se o dispõe numa categoria jurídica, e a função lógica de estrutração do fato, em geral, por parte do, espírito.

Enfim, para Sauer, a Verdade total, a "Verdade verdadeira", é a reunião harmônica das três grandezas - Fato, forma e valor regulativo ("Die wahre Wahrheit kann nur die harmonische Vereinigung der drei Groessen - Tatsachen, Form und regulativen Werte sein") (loc. cit.). 
Para nós, devemos dizer que é incompreensível como alcançar-se esta unificação harmônica de fato, norma e valor - a não ser através do espírito, o qual, como forma, é a função ou o princípio funcional que sintetiza os três têrmos; do nosso panto-de-vista, é impossível uma consideração ontológica dessa última unidade, fora do espírito. $O$ espírito é justamente o centro funcional dessa unificação, que permanece dotada de uma validez absoluta e objetiva. O espírito aí, como função unificadora, nada tem a ver com qualquer processo psicológico, mas é o reflexo do Logos eterno, como lei dessa função, princípic supremo, e porisso mesmo - mas tão-sòmente por isso - metafísico.

Quanto ao absoluto do valor, só podemos compreende-lo como idéia. Esta Idéia porém, é a generalidade das possibilidades lógicas das condições de relação. Como tal lei da relação dialética de condição, o absoluto como Idéia é objetivo e incondicionadạmente válido (e portanto, o relativismo histórico não é, como muitos pensam, a única solução, com referência à objeção acêrca da variabilidade dos conteúdos).

Esta posição tem seu ponto de arranque num ponto-de-vista gnoseológico, mas não gnoseológico stricto-sensu, no sentido dos logicistas puros (escola de Marburgo, pr exemplo), mas no sentido de um Bruno Bauch ou de Hoenigswald (portanto de um kantismo influenciado por conceitos provenientes de Hegel e genèricamente do Idealismo alemão), e também no sentido de um Ruggiero (última posição do mesmo), especialmente no que se refere ao princípio dialético.

Constitui uma posição, portanto, que representa a tentativa, sempre renovada, de conciliar metafísica (no sentido do simplesmente transcendente) e lógica. Ambas encontram-se no conceito "planteístico" de um Logos, do qual são duas partes, e o qual se revela e se realiza através do espírito do eu (como totalidade das funções estruturantes, e portanto constitutivas e condicionantes do ser e do valor).

O Logos, pois, é compreendido, tanto como a totalidade das condições das relações de validez, lógicas objetivas (mundo), (e neste sentido, o "ser" e o "valor" não são conceitos últimos, mas são compreendidos sòmente enquanto são condicionados pela sua validez; e portanto, como todos os outros conceitos, são condicionados funcionalmente) e também como condição do Pensar em si. 
Só através do espírito de tal maneira entendido é que pode, a nosso ser, revelar-se a suprema unidade do processo. Para nós, na realidade, é a oposição dialética justamente a expressão da unidade do processo, fragmentada de certa maneira justamente pela posição até aqui analisada, com sua passagem injustificada do "fato" para a norma e o valor, e com o seu estranho conceito do "fato" como postulado. A êste conceito de oposição, pois, ao qual nos referimos acima, e que, quanto ao direito, cifra-se no contraste entre direito positivo-imperfeito - e "Direito ideal" - a êste conceito de oposição teremos de voltar, para compreender o problema jus-filosófico do Faust.

No Faust há uma série de contrastes, de aparentes contradições que revelam, na realidade, a síntese, a unidade da qual são expressão, e cuja breve consideração proporcionará com maior clareza uma compreensão do problema que nos ocupa. Daremos dois breves exemplos.

Faust apresenta-se, desde o início, em sua inquietude e insatisfação, com uma tensão (Spannung) entre o bem e o mal, "em seu peito habitam duas almas", uma que o prende à materia, outra que o impele para os valores mais altos:

Zwei Seelen wohnen ach, in meiner Brust

Die eine will sich von der andern trennen.

Faust, que quer o bem e faz o mal, é de certa maneira oposto a Mefisto o qual, ao contrário, quer o mal, mas faz o bem, como êle diz de si próprio: "eu sou"

"Ein Teil von jener Kraft

Die stets das Boese will und stets das Gute schafft.

Contradição há, também, no próprio Mefisto, que por um lado condiciona em parte a realização de valares de Faust (promove o bem), mas ao mesmo tempo, sempre foi a sua parte má, como o demonstram a história de Margarida e o episódio de Baucis e Filemon. Neste episódio, Faust, senhor de tôda a região que queria transformar para bem de milhares, encarrega a Mefisto de deslocar um casal de velhos - 
Baucis e Filemon - e sua residência. Mefisto, em vez de cumprir a ordem de Faust, destroi e incendia a casinha, matando os infelizes. E. Faust, ao receber a notícia, exclama irado:

Wart ihr fuer meine Worte Taub!

Tausch wollte ich, wollte keinen Raub.

"Fostes surdos às minhas palavras.

Troca eu queria, e não latrocínio!

Cumpre-se aqui também o destino de Faust, porque êle, na realidade, queria o bem, mas cumpria o mal; se cumpria o mal, queria, entretanto, o bem.

A unidade é vislumbrada através relação dialética que existe em tôdas essa contradiçōes, e particularmente entre Faust e Mefisto. Porque, apesar de tudo, e especialmente do que parece o maior paradoxo, ou seja a indireta criação de bem por parte de Mefisto, a unidade da qual tudo provém, e na qual vige uma "coincidentia oppositorum", é implícita em todos os momentos e em tôdas as oposições. Elas não são, com efeito, sinão a cisão da Unidade que é príncipio e fim do processo. Alfa e Ômega. O próprio Mefisto, decifrando a íntima contradição que o anima, dá a entender o sentido dêsse "Um", do qual êle, e Fausto provêm:

Ich bin ein Teil des Teils, der Anfangs alles war, Ein Teil der Finsternis die sich das Licht gebar

Eu sou uma parte da parte, que no princípio era o todo, Uma parte das trevas, que geraram a luz.

Outra oposição que impressiona, no Faust, é aquela que parece existir entre Natureza e Espírito. Aqui, Faust revela-se como descontente com sua vida de estudioso, em que se acha rodeado" por môfo e esqueletos" e ansioso por aprofundar-se na natureza, e captá-la. Afirma desprezar a "ciência", aquela mesma ciência que provoca os entusiasmos de Wagner, o seu pedante criado, que responde ao amor demonstrado. por Faust pela natureza" que as alegrias do espírito, que nos levam de: pagina em página, de livro em livro, são muito mais atraentes": 
Wie anders tragen uns die Geistesfreuden

Von Buch zu Buch, von Blatt zu Blatt.

Wagner entendé a natureza escolàsticamente, como um dado oferecido à razão científica, estreita e classificadora. E o próprio Mefisto não ultrapassa o dualismo de "dado" - e "saber" racional, tanto que se alegra por instilar-se como crê, em Faust, o desprêzo pela ciência, ou seja o amor àquilo que para êle representa a matéria e os prazeres físicos.

A verdade é que em Faust realiza-se uma síntese que ultrapassa o dualismo, porque êle intui na natureza justamente o espírito, que a "ciência" só, é incapaz de captar, espírito êsse que se reflete, ao mesmo tempo, no próprio Faúst, e que forma uma unidade com o seu próprio espírito. E' através do seu espírito, efetivamente, que Faust intui a Natureza como espírito. Eis aí o sentido desta unidade: a natureza é espírito justamente enquanto como tal é captada pelo espírito como pensamento.

Pois bem, além das oposições citadas, cuja análise acabamos de fazer, e que nos serviram de paralelo, há, como vimos, uma outra, que mencionamos no início dêste estudo. $\mathbf{E}^{\prime}$ justamente a oposição entre direito positivo e direito ideal, direito temporal, histórico, e direito supratemporal.

Ora bem, quanto ao ponto-de-vista da Idéia de Direito, e de como ela, através, principalmente, da aposta, é expressa no Faust, poderiamos chegar às conclusões seguintes: assim como a oposição entre bem e mal, expressão da dialética do espírito em seu específico momento ético, e a oposição entre natureza e espírito, expressão stricto-sensu da dialética entre a expressão material e sensível do cosmos e do que no cosmos se reali$z a$, e o espírito com seu condicionante, assim como essas oposições, dizemos, se resolvem numa unidade que as abrange, assim também o direito, aparentemente dividido em dois, é, no fundo, um único processo, que se revela como tal justamente na oposição; porque, como bem e mal, também justo e injusto não podem compreender-se sinão um referido ao outro, momentos dialéticos de um mesmo princípio. Esta é, digamos assim, a expressão da Idéia de Direito como um todo, em seu aspecto cósmico, ao qual, entre outros, se refere Rodolfo Mondolfo (5). 
E talvez seja esta uma das significações da frase de Ulpiano acerca da jurisprudência. Fiados na significação que juris-prudentia tinha para os romanos, de ciência - no bom sentido, poderíamos talvez referirnos a essa frase, com referência ao aspecto cósmico de Ordem e proporção total, e aplicando-a ao direito em seu todo, dizer que êle é realmente "divinarum atque humanarum rerum notitia, justi atque injusti scientia",

Se não tivéssemos limitado, de certa maneira, estas considerações sôbre a posição de Goethe perante a Idéia de Direito, ao Faust, caberia neste momento analisarmos dois conceitos que no que se refere àquela idéia, são em Goethe de enorme importância, e que se referem especialmente àquele conceito de Ordem, revelando mais uma vez a validez do princípio de síntese dialética de contrários: são os conceitos de Ordem e de revolução. Estes conceitos, em si, encerram uma problemática fecunda, no que diz respeito, talvez, ao fundamento mesmo de qualquer direito positivo, e de suas relações com o "direito eterno", e aos fatores importantíssimos de estaticidade e de renovação da ordem jurídica. Para nós, no fundo, êste fundamento último é, no que tange o seu aspecto histórico, um problema estritamente ligado à questão da justificação do princípio de revolução como renovação violenta de uma ordem jurídica històricamente superada. Iríamos longe, entretanto, se nos detivéssemos na consideração dêstes problemas. Desejamos apenas frisar a sua relação com os conceitos de formalismo e de justiça concreta que formam, a nosso ver, o fulcro da posição jurídica de Goethe no Faust. Goethe, certa vez, afirmara, que se tivesse de escolher entre a Ordem e a Justiça, escolheria a Ordem. Qual a significação dêste dilema? Será porventu. ra injusta a escolha da Ordem frente à justiça? O que importa, aí, é não identificar-se Justiça com direito positivo, especialmente em seu sentido de relação; ou seja, não esgotar o direito no direito positivo. Nesta conexão, surge, se bem analisado o problema, a possibilidade de uma superação do aparente dualismo numa síntese singular. Porque, no primeiro plano - o do direito positivo (no qual existe o conflito entre a ordem como segurança e a justiça como liberdade) a justiça que é compreendida como proporcionalidade e "segurança", visa impedir o prejuízo injusto causado à pessoa como sujeito de direitos, pela mutabilidade e a irregularidade ou o arbítrio das dispisições - e esta segurança estará necessàriamente representada pelo formalismo da ordem jurídica. 
Surge assim, entretanto, uma nova relação entre duas partes, imprevistas, surge uma exigência nova de justiça: aqui, a proporcionalidade é entendida, de certa maneira, entre a comunidade, representada por cada uma de suas partes, e a própria ordem jurídica que deve preservar a segurança. As duas partes entre as quais a segurança jurídica preserva a proporcionalidade como justiça, são - de um lado - o sujeito de direitos - e do outro - a Ordem Jurídica. Esta, como direito objetivo, torna-se uma das partes da relação - Ordem jurídica - sujeito de direito; a segurança (comumente oposta à realizabilidade da justiça) é aí como uma prestação da Ordem jurídica ao sujeito de direitos, e esta nova relação ideal, em que surgem dois aspectos de direito, dois momentos de justiça, é regulada não mais por uma outra Ordem jurídica, mas pela própria Justiça como totalidade dialética, numa síntese que supera a própria oposição entre segurança jurídica e justiça concreta.

Voltando ao Faust, a característica dialética da necessidade de referência recíproca dos momentos de justo e injusto, à qual nos referimos, poderia, no plano da essência lógica do direito, ser ilustrado com a reflexão de que a norma é norma, justamente enquanto susceptível de ser violada; do contrário, não possui justificação lógica.

Concluindo, para Goethe - o que alguns não entendem - "ação" é entendida como dinâmica do espírito, oposta à estaticidade de princípios rígidos. Goethe admite a unidade do processo divino no mundo. Mas, quanto ao mal, é para êle um polo necessário do bem. Para êle, o espírito é e deve ser perene renovação: "Enquanto não tiveres êste morre e ressuscita! serás um obscuro hóspede neste mundo":

Und solang du das nicht hast

Dieses; stirb und werde!

Bist du nur ein trueber Gast

Auf der dunklen Erde.

Também no direito há o mal: é a própria imperfeição de sua realizabilidade. Mas porisso mesmo, vale uma Justiça ideal que o redima. De qualquer forma, é quando o mal prevalece sôbre o bem, que o bem deve ser uma conquista. E' então que podemos cantar, com o côro dos espíritos: 


\section{Prächtiger baue sie wieder, \\ In deinem Busen baue sie auf! \\ Neuen Lebenslauf beginne \\ Mit hellem Sinne \\ Und neue Lieder \\ Toenen darauf!.}

"Aquêle maravilhoso mundo, que foi destruido, reconstrói-o com maior esplendor, reconstrói-o no teu íntimo; inicia, com novo sentido, o caminho da vida, e sejam entoados, nas alturas, novos cânticos".

\section{$\mathrm{N} O \mathrm{~T} A \mathrm{~S}$}

(1) Del Vecchio - "La crise de la science du Droit" in "Justice, Droit, Etat", 1938, pp. 93-112.

(2) Como nos ensinou nosso eminente amigo Abrahão Ribeiro. (3) "L'Idèe de Convention et ses realités juridiques" - in "Archives de
Philosophie du Droit et de Sociologie juridique" - 1940, n.0 1.-4; pp. 110-158.

(4) "L'homo juridicus et l'insuffisance du droit comme règle de la vie", in "Justice, Droit, Etat".

(5) "Naturaleza y Cultura en los origenes de la filosofia", in "En los origenes de la filosofia de la Cultura" - Buenos Ayres, 1942. 